\title{
The value of magnetic resonance imaging geometric parameters in pre-assessing the surgical approaches of pelvic fracture urethral injury
}

\author{
Zeyu Wang ${ }^{1,2 \#}$, Guoping Song ${ }^{3 \#}$, Yunfeng Xiao ${ }^{3}$, Tao Liang ${ }^{1,2}$, Feixiang Wang ${ }^{4}$, Yubo Gu ${ }^{1,2}$, Jiong Zhang ${ }^{1,2}$, \\ Yuemin $\mathrm{Xu}^{1,2}$, Sanbao Jin ${ }^{1,2}$, Qiang Fu ${ }^{1,2}$, Lujie Song ${ }^{1,2}$ \\ ${ }^{1}$ Department of Urology, Shanghai Jiao Tong University Affiliated Sixth People's Hospital, Shanghai, China; ${ }^{2}$ Shanghai Eastern Institute of Urologic \\ Reconstruction, Shanghai, China; ${ }^{3}$ Department of Radiology, Shanghai Jiao Tong University Affiliated Sixth People's Hospital, Shanghai, China; \\ ${ }^{4}$ Shanghai Key Laboratory of Forensic Medicine, Academy of Forensic Science, Shanghai, China \\ Contributions: (I) Conception and design: Z Wang, G Song, F Wang, Y Gu, L Song; (II) Administrative support: F Wang, Q Fu; (III) Provision of \\ study materials or patients: T Liang, J Zhang, Y Xu, S Jin, Q Fu, L Song; (IV) Collection and assembly of data: Z Wang, G Song, Y Xiao, T Liang, J \\ Zhang, Y Xu, S Jin, Q Fu, L Song; (V) Data analysis and interpretation: Z Wang, G Song, Y Xiao, F Wang, Y Gu, L Song; (VI) Manuscript writing: \\ All authors; (VII) Final approval of manuscript: All authors. \\ \#These authors contributed equally to this work. \\ Correspondence to: Lujie Song, MD; Qiang Fu, MD. Department of Urology, Shanghai Jiao Tong University Affiliated Sixth People's Hospital, \\ Shanghai 200233, China. Email: ljsong@sjtu.edu.cn; jamesqfu@aliyun.com.
}

Background: To investigate the correlation between the magnetic resonance urethrography and the surgical approach and complexity for the patients with pelvic fracture urethral injury (PFUI) by combining the geometry with magnetic resonance imaging (MRI).

Methods: Forty-three male patients with PFUI (part of the patients complicated with rectal injury) from January 2016 to December 2018 were analyzed in this retrospective research. All the patients underwent a delayed anastomotic urethroplasty and were divided into 2 groups according to the approaches (simple perineal approach or inferior pubectomy). For magnetic resonance urethrography, we measured and calculated the geometric parameters such as the gap distance between two urethral ends, the pubourethral vertical distance (PUVD), and the rectourethral median distance (RUMD).

Results: Of the 43 patients, 16 underwent inferior pubectomy and 27 underwent simple perineal approach. The numbers of patients with and without rectal injury history were 17 and 26, respectively. The operation time and intraoperative blood loss was significantly higher in the inferior pubectomy group. Multivariate logistic analysis revealed that gap distance and PUVD were independent factors of the surgical approaches. The accuracies were $83.7 \%$ and $67.4 \%$ respectively in the ROC curve analysis. In addition, the RUMD was significantly shorter in the patients with rectal injury history $(1.4,1.8 \mathrm{~cm})$.

Conclusions: Longer gap distance and shorter PUVD were the two independent factors of the inferior pubectomy approach. Furthermore, among the patients with rectal injury history, the tissue posterior to the urethra was often weaker and should be carefully handled during the surgery.

Trial registration: This research has been registered on the Chinese Clinical Trial Registry. The registration number is ChiCTR2000030573.

Keywords: Magnetic resonance imaging (MRI); urethral stenosis; urethroplasty; reconstructive surgical procedures

Submitted Jul 05, 2020. Accepted for publication Sep 28, 2020.

doi: $10.21037 /$ tau-20-1064

View this article at: http://dx.doi.org/10.21037/tau-20-1064 


\section{Introduction}

The incidence of pelvic fracture urethral injury (PFUI) is reported with a high rate in many developing countries like China. Most of the PFUI cases are caused by traffic accidents, especially the pedestrian and cycle-related mishaps which lead to serious complications such as rectal perforation, fistula (1-4). Currently, the gold standard for the treatment is the delayed anastomotic urethroplasty, performed through the perineal approach (5-7). This surgical approach includes the complete excision of the fibrotic urethra and cavernosum and a tension-free primary anastomosis of the two healthy urethral ends (8). Additionally, surgeons often use techniques such as mobilizing the distal urethra completely, corporal splitting, inferior pubectomy, and supracrural rerouting to reveal the proximal urethral anastomotic stoma and achieve a tensionfree anastomosis, which may further increase the surgical complexity (9).

However, the complexity associated with the surgical intervention still cannot be estimated accurately (10). Although useful, the combined retrograde urography (RGU) with voiding cystourethrogram (VCUG) is limited by being a two-dimensional representation (11). MRI has been used in evaluating PFUI since 1992 (12). Up to now, researches have shown that MRI is an ideal tool in assessing urethra because of its non-invasive, non-radioactive, multiplanar capability and high tissue contrast (13-15). Therefore, we used magnetic resonance (MR) urethrography for the preoperative assessment of PFUI and investigated the correlation between the MRI geometric parameters and surgical approaches and complexity. We present the following article in accordance with the STROBE reporting checklist (available at http://dx.doi.org/10.21037/tau-201064).

\section{Methods}

\section{Patient selection}

Patients who underwent a delayed anastomotic urethroplasty for treating the PFUI during the January 2016 to December 2018 in Shanghai Jiao Tong University Affiliated Sixth People's Hospital by a single surgical team were screened. All patients who were subjected to a preoperative dynamic contrast-enhanced MR urethrography were included in this retrospective analysis. Considering the development of the prostate, patients younger than 16 were excluded, and finally, 43 patients were enrolled in.
RGU and VCUG were finished routinely. If the patient was considered a complex posterior urethral stenosis, MR urethrography would be performed. A complex posterior urethral stenosis was defined as stenosis length $>3 \mathrm{~cm}$, associated with perineal recto-urethral fistulas, periurethral cavities, false passages, diverticula, injured sphincter or failed urethra reconstruction history $(8,16)$. All the included patients had an indwelling suprapubic tube (SPT) before the operation and were more than 3 months away from the urethral injury or the last transurethral treatment. The study was conducted in accordance with the Declaration of Helsinki (as revised in 2013). The study was approved by the ethics committee of Shanghai Jiao Tong University Affiliated Sixth People's Hospital (Ethic batch number: 2020-KY-007) and individual consent for this retrospective analysis was waived.

\section{Magnetic resonance urethrography and parameters}

MR urethrography were performed by a single experienced radiologist using 3T MRI systems (Magnetom Spectra; Siemens, Erlangen, Germany). Before scanning, the normal saline was injected into the bladder and anterior urethra through the SPT and urethral orifice until the micturition desire was aroused. The glans was tightened by a springy band with gauze advance. A pelvic phased-array coil was used and following scanning sequences were included: (I) axial T1-weighted imaging [repetition time $(\mathrm{TR})=555$, echo time $(\mathrm{TE})=9.9,20 \mathrm{~cm} \times 20 \mathrm{~cm}$ field of view, $3.0 \mathrm{~mm}$ thickness with $2.8 \mathrm{~mm}$ gap]; (II) sagittal, axial, and coronal $\mathrm{T} 2$-weighted imaging $(\mathrm{TR}=4,500, \mathrm{TE}=125,20 \mathrm{~cm} \times$ $20 \mathrm{~cm}$ field of view, $3.0 \mathrm{~mm}$ thickness with $2.5 \mathrm{~mm}$ gap); (III) enhanced 3-dimensional T1 gradient echo sequence ( TR $=5.7, \mathrm{TE}=2.5,20 \mathrm{~cm} \times 20 \mathrm{~cm}$ field of view, $2.5 \mathrm{~mm}$ reconstructed thickness with $2.5 \mathrm{~mm}$ gap).

Based on the images, the geometric parameters were of particular concern to us (Figure 1), especially the following ones: (I) gap distance between two urethral ends (GD); (II) pubourethral vertical distance (PUVD), defined as the vertical distance from the inferior margin of pubis to the line connecting two urethral ends; (III) rectourethral median distance (RUMD), defined as the distance from the anterior rectal wall to the middle point of the line connecting two urethral ends. The PUVD was calculated by Heron's formula (17), and the RUMD was calculated by Apollonius' theorem (18).

Besides, we evaluated each patients' pelvic fracture type. The pelvic fracture was divided into four levels. Single 

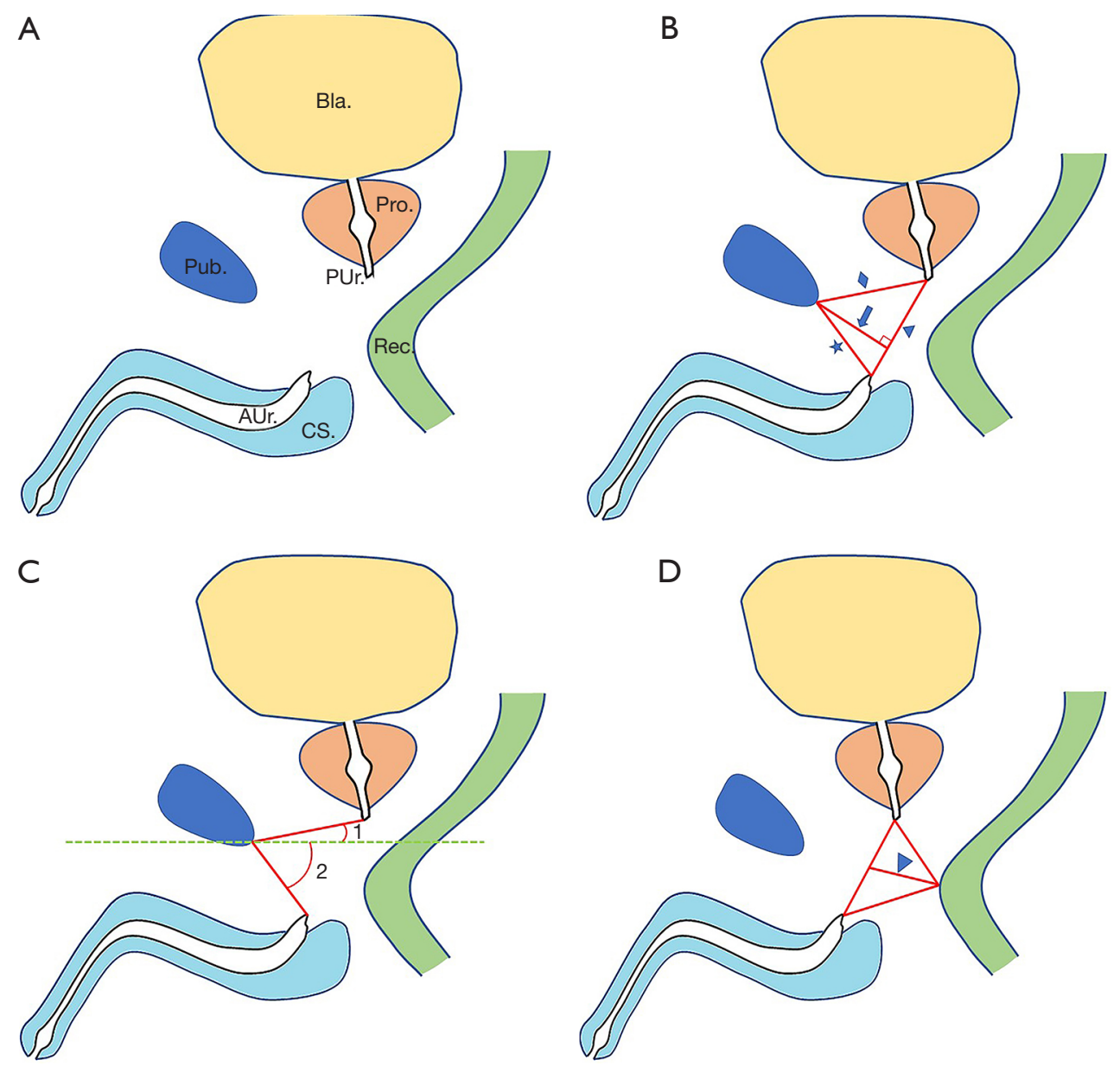

Figure 1 pelvic fracture urethral injury (PFUI) and magnetic resonance imaging (MRI) parameters. (A) General situation about PFUI. Bla, bladder; Pro, prostate; Pub, pubis; Rec, rectum; CS, corpus spongiosum; PUr, posterior urethra; AUr, anterior urethra. (B) The parameters of distance associated with the pubis. Arrows, pubourethral vertical distance (PUVD); Triangle, gap distance between two urethral ends (GD); Rhombus, the distance from the inferior margin of the pubis to the proximal urethral end; Star, the distance from the inferior margin of the pubis to the distal urethral end. (C) The parameters of angles associated with the pubis. Angle 1, proximal horizontal angle; Angle 2, distal horizontal angle. (D) The distance associated with the rectum. Triangle, rectourethral median distance (RUMD).

ramus fracture, ipsilateral both pubic rami fracture, bilateral two or more rami fracture, and furtherly with disruption of ipsilateral sacrum, sacroiliac joint or femur neck graded from level 1 to 4 (19). The numbers of pubic symphysis diastasis were also assessed.

All parameters were measured independently by two experienced radiologists who were blinded to the patients' clinical history.

\section{Delayed anastomotic uretbroplasty}

Delayed anastomotic urethroplasty was performed in all cases. First, an inverted " $T$ " incision was made in the middle of the perineum and urethra was divided at the obliteration segment. The distal urethra was mobilized and scar tissue was completely excised. Then, an appropriate sound was placed through the SPT tract to locate the proximal urethral end. In order to sufficiently reveal the healthy mucosa and prepare for the subsequent suture and tensionfree anastomosis, corporal splitting and further inferior pubectomy would be considered. When the tension-free anastomosis is feasible, a Foley catheter was inserted and 8 radially placed 4-0 coated vicryl absorbable sutures (Ethicon; Cincinnati, Ohio, USA) were used for suture. Patients who underwent direct anastomosis or only corporal splitting were considered a simple perineal approach group. Those 
Table 1 Univariate analysis of demographic information between simple perineal approach group and inferior pubectomy group

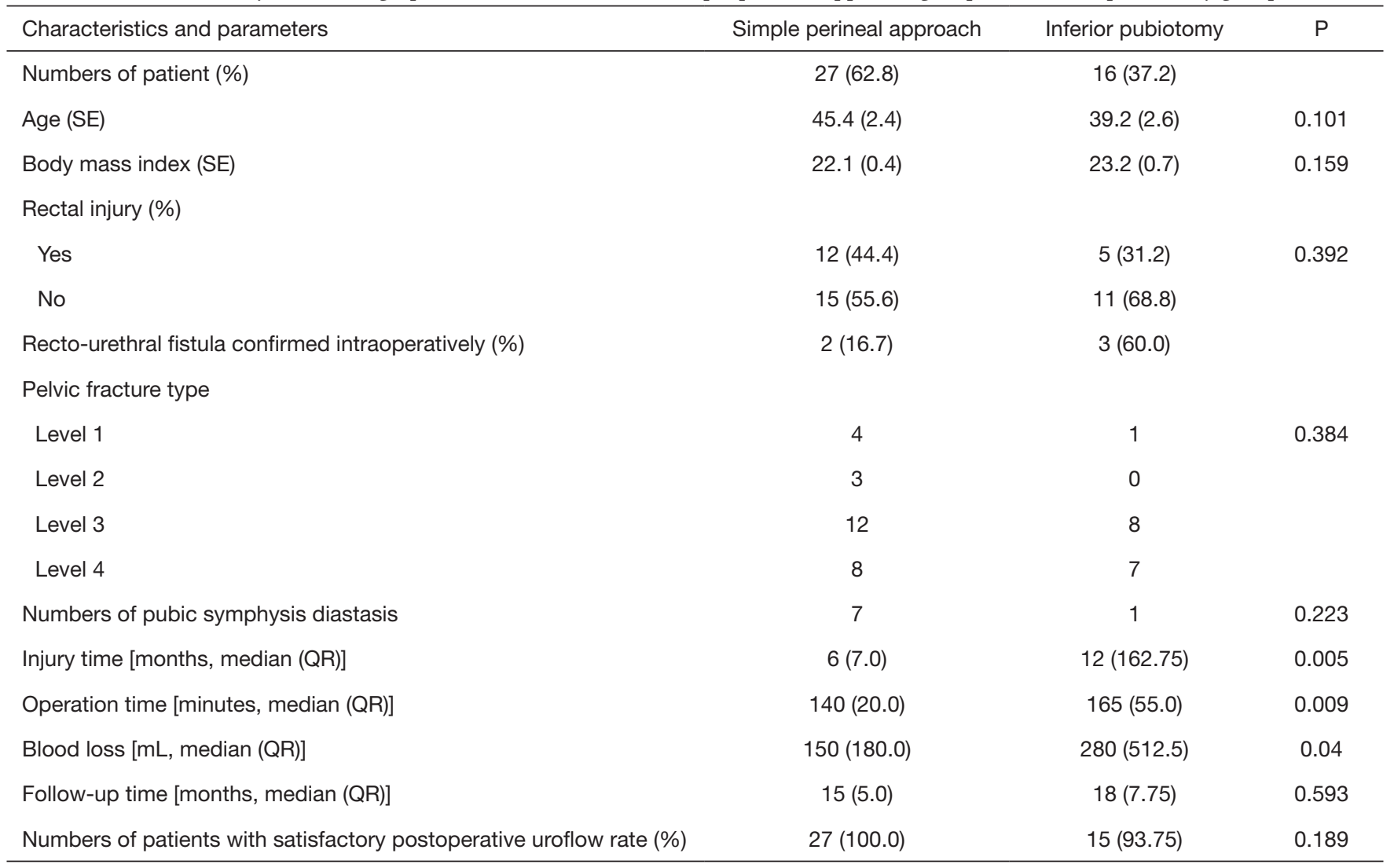

$\mathrm{SE}$, standard error; $\mathrm{QR}$, quartile range.

who underwent inferior pubectomy were considered to be in the inferior pubectomy group. If the recto-urethral fistula was confirmed, it would be separated and sutured to close.

The urethral catheters were removed after 4 weeks with a uroflowmetry. One week after, if the anastomotic stoma recovered well and no obvious scar tissue was observed through a flexible cystoscope, the SPTs would be removed. At 3, 6 and 12 months after surgery, uroflowmetry was performed routinely. When the uroflow rate kept greater than $15 \mathrm{~mL} / \mathrm{sec}$ and no further surgical interventions were needed, the operation was considered successful.

\section{Statistical analysis}

For categorical variables, the chi-square test was used to evaluate the correlation between variables and groups. The Student's $t$-test was used to evaluate the correlation of continuous variables when obeying normal distribution, and the non-parametric Mann-Whitney $U$ test was used when not. Variables matching with a significant correlation with the groups were included in univariate logistic regression. And multivariate model was done according to the results. Finally, the ROC curve was elucidated. Besides, patients with missing data would be excluded.

All statistical analyses were performed on SPSS Statistics software (SPSS, RRID:SCR_002865) version 17.0. A P value less than 0.05 was considered statistically significant.

\section{Results}

\section{Basic characteristics}

A total of 45 patients with PFUI underwent MR urethrography. Two patients were excluded because of the age and the absence of delayed anastomotic urethroplasty, respectively. Among 43 patients, 27 (62.8\%) were included in the simple perineal approach group and $16(37.2 \%)$ were in the inferior pubectomy group (Table 1). The median follow-up time was 15 [12-30] months. Subjects ranged in 
Table 2 Univariate analysis and multivariate logistic regression analysis of MRI geometric parameters between simple perineal approach group and inferior pubectomy group

\begin{tabular}{|c|c|c|c|c|c|c|}
\hline $\begin{array}{l}\text { MRI geometric } \\
\text { parameters }\end{array}$ & \multicolumn{3}{|c|}{ Univariate analysis } & \multicolumn{3}{|c|}{ Multivariate logistic regression analysis } \\
\hline Gap distance (cm, SE) & $1.3(0.1)$ & $2.1(0.2)$ & $<0.001$ & 2.33 & $1.30-4.17$ & 0.005 \\
\hline $\begin{array}{l}\text { Pubourethral vertical } \\
\text { distance (cm, SE) }\end{array}$ & $1.6(0.1)$ & $1.2(0.1)$ & 0.039 & 0.56 & $0.36-0.88$ & 0.011 \\
\hline $\begin{array}{l}\text { Distal pubourethral } \\
\text { distance (cm, SE) }\end{array}$ & $1.9(0.1)$ & $1.6(0.2)$ & 0.284 & & & \\
\hline $\begin{array}{l}\text { Proximal horizontal angle } \\
\text { (degree, SE) }\end{array}$ & $-11.9(4.9)$ & $-30.1(4.9)$ & 0.018 & 1.05 & $0.98-1.13$ & 0.193 \\
\hline
\end{tabular}

OR, odds ratio; $\mathrm{Cl}$, confidence interval; SE, standard error.

age from 17 to 66 years, and the median age was 46 years. No statistically significant difference was noticed. The body mass index (BMI) ranged from 16.6 to 26.7 (mean: 22.5). The median of injury time (month) in two groups was 6 and $12(\mathrm{P}=0.005)$. In simple perineal approach group, 12 (44.4\%) and in inferior pubectomy group 5 (31.2\%) patients were accompanied with a history of rectal injury respectively, and there was no statistically significant difference. The distribution of pelvic fracture type kept the similar trend in two groups. We compared the operation time and intraoperative blood loss for the complexity of two surgical approaches. The median of these two parameters in the simple perineal approach group and the inferior pubectomy group were 140 vs. 165 minutes, and 150 vs. $280 \mathrm{~mL}$. Both were significantly higher in the latter group ( $\mathrm{P}=0.009 / 0.04)$. Till the latest follow-up, the success rate of the approaches was $100 \%$ and $93.75 \%$ respectively. Only one patient in inferior pubectomy group had a dissatisfied uroflow with anastomotic stenosis postoperatively. A penis transposition urethral anastomosis (20) was performed later and resulted in a satisfactory postoperative uroflow rate. But the patient developed stress incontinence, and currently managed with the penis clamp for urine control.

\section{Surgical approaches and MR urethrography}

We have analyzed 6 geometric parameters of MR urethrography (Table 2). In the univariate analysis, GD, PUVD, the proximal horizontal angle and injury time showed a significant correlation with two surgical approaches. Injury time was denied by the univariate logistic regression analysis. Whereas the multivariate logistic regression analysis revealed that GD and PUVD were two independent factors for the surgical approaches of PFUI. The GD was regarded as a risk factor, but the PUVD was a protective factor.

Finally, the ROC curve of GD and PUVD showed that the area under the curve was 0.88 and 0.70 respectively with the corresponding best cut-off points $1.55 \mathrm{~cm}$ both. The sensitivity, specificity, and diagnostic accuracy of GD were $87.5 \%, 81.5 \%$, and $83.7 \%$, and for PUVD were $59.3 \%$, $81.2 \%$, and $67.4 \%$.

\section{Rectal injury and MR urethrography}

Among these patients, 17 (39.5\%) had rectal injuries and $26(60.5 \%)$ did not. Five of seventeen $(29.4 \%)$ patients, were intraoperatively confirmed to have a recto-urethral fistula. The rest 12 patients spontaneously healed with or without a colostomy. Univariate analysis showed that RUMD was significantly shorter in patients with rectal injury $(1.4 v s .1 .8 \mathrm{~cm}$, $\mathrm{P}=0.004)$.

\section{Discussion}

Delayed anastomotic urethroplasty is still preferred as the most recommended treatment for PFUI (5-7). Routinely, a RGU with VCUG and/or cystourethroscopy 
will be performed preoperatively to assess the possible intraoperative conditions, especially for the selection of surgical approaches. However, even with these preassessments, intraoperative discovery remains a key factor in decision making. In our study, all the chosen patients were treated by one single surgical team to minimize the subjective bias caused by the intraoperative decisions of different surgeons. Considering the difficulty and damage caused by the inferior pubectomy, it should be considered only if the proximal urethra cannot be revealed or a tension-free anastomosis is still not possible after the mobilization of the distal urethra and corporal splitting has been done. The study of Horiguchi et al. (21) reported that both the operative time and intraoperative blood loss were significantly higher in the elaborate approach group, which was consistent with our findings. Besides, inferior pubectomy could bring more postoperative erectile dysfunction (22). Lue et al. (23) proved cavernous nerves run closely from the 5 and 7 o'clock positions of prostatic apex to the 1 and 11 o'clock positions of proximal bulbous urethral. In patients requiring pubectomy, the proximal urethra ends are often immediately behind inferior margin of the pubis which make the cavernous neurovascular bundles vulnerable to be hurt in the process. Therefore, a reference was needed for the surgeons to estimate the complexity of the surgical procedure and to inform the patients about the risk. Preoperative MRI, which had been widely used in assessing urinary tract associated diseases could inevitably provide a pre-assessment of the complexity (24). Compared to RGU with VCUG, MR urethrography has the characteristics of non-invasive, non-radiative, less painful and three-dimensional representation. Furthermore, in these assessments geometry played an irreplaceable role. Collectively, the images became more analyzable and contrastive to derive a rapid and conclusive remark with a feedback on the clinical decision (25-27).

The GD parameter was initially considered. In a study conducted by Sung et al. (28), due to the insufficient urethral filling and artificial traction, the length of urethral stenosis was overestimated in 6 of the 10 patients who underwent RGU with VCUG. In contrast, the error of MR urethrography in evaluating urethral stenosis length showed significantly smaller values. However, Osman et al. (29) reported that no significant difference was observed. In our study, we paid more attention to perform earlier scanning immediately after injecting the intravenous contrast agent, so that we could establish the healthy urethral and rectal mucosa even in those cases with an incomplete urethral filling (Figure 2). Our modifications could achieve more accurate geometric parameters. The precise locations and enthesis of the fistulas, diverticula and false passages could also be accurately judged. Besides, Koraitim's study (30) showed positive correlation supporting the GD's influence in urethrogram. However, Andrich et al. (31) after conducting a study through traditional radiological data of 62 patients have reported a contradictory statement mainly by pointing out the inherent defect of the 2-dimensional $\mathrm{X}$-ray. In our study, the multivariate analysis and ROC curve, both have confirmed the significant value of GD as an independent risk factor of surgical approaches.

In some cases, due to pelvic fracture, it was noticed that urethra was displaced forward and upward. This slight displacement could make the proximal urethral end hidden behind the pubis, and may obstruct the surgeon's view of surgical field, and complicated the anastomosis (31). According to our experience, if the proximal urethral ends were far away from the inferior margin of the pubis and close to the distal urethral ends, surgeons could get enough space to make sutures and achieve the tensionfree anastomosis. Therefore, we constructed a triangle, making the inferior margin of pubis, ends of the proximal and distal urethra as the vertices to intuitively illustrate this relationship. The PUVD was included in the statistical analysis which confirmed the positive correlation. When the PUVD was small, the pubis seemed to be inserted between the two urethral ends, and the surgeons would most likely need to remove its inferior margin to achieve a satisfactory surgical field and a tension-free anastomosis (Figure 3).

Intraoperative rectal injury is also a major concern. Corriere et al. (32) have reported a 3\% incidence in a study of 60 patients who underwent urethroplasty because of posterior urethral rupture. These injuries of scarification and burning might have happened during the excision of scar tissue. Therefore, the parameters of RUMD was set to represent the relationship between the anterior rectal wall and the defective urethra which needs to be operated. The analysis showed that for patients with rectal injury history, the RUMD was significantly smaller than those without. This analysis critically signifies that thorough preoperative intestinal preparation is mandatory to protect the rectum from intraoperative damage in such patients. In addition, in contrast enhanced images, the various layers of the rectum are clearly represented, especially the rectal mucosa and the rectal wall, which is useful for assessing the relationship between the rectum and the injured urethra.

Our study has some limitations. Firstly, this research was 

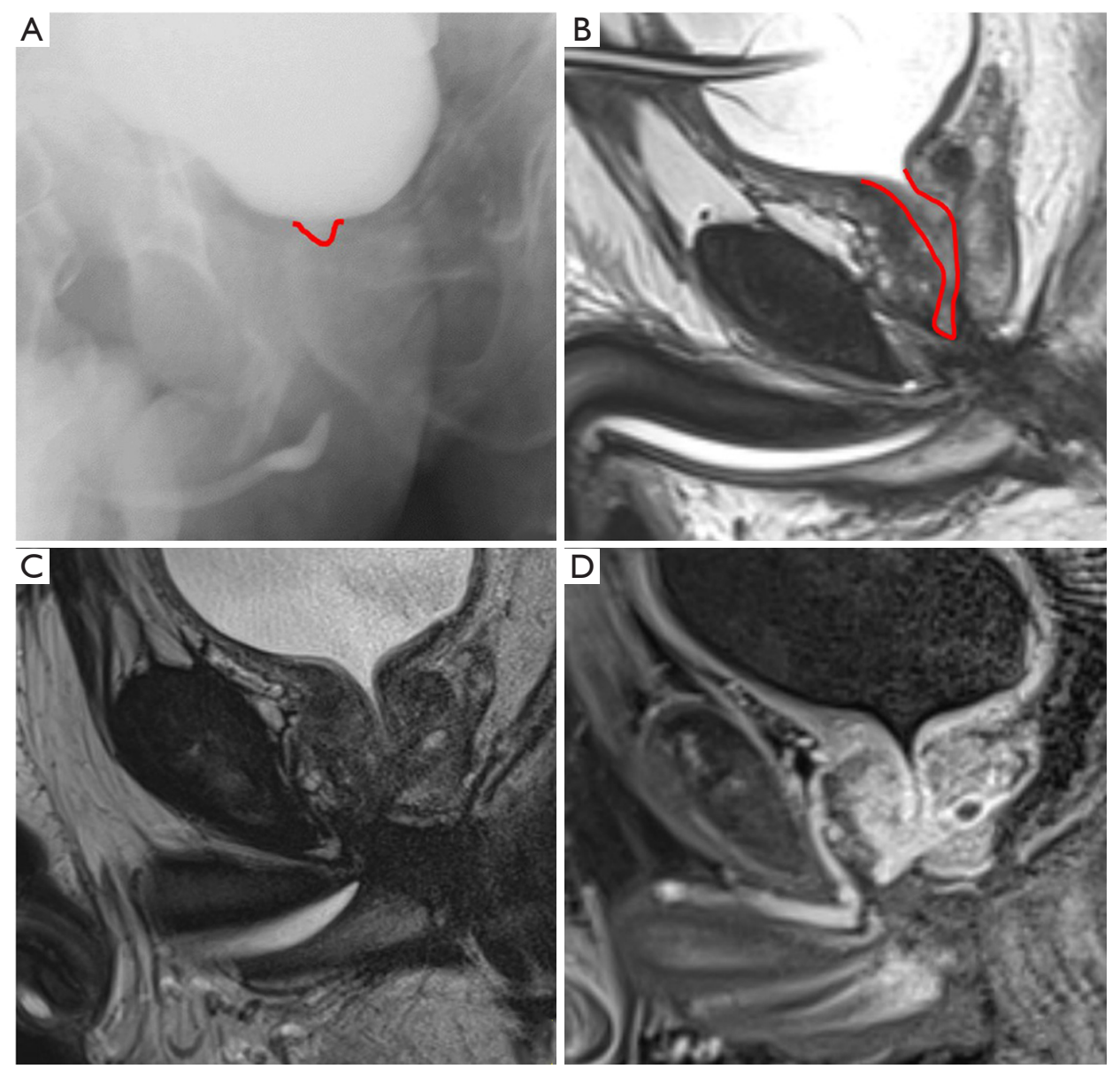

Figure 2 Urethral stenosis in different imaging examinations. (A,B) The urethrogram and MR urethrography of a same patient. Neither of them had a complete urethral filling. However, the urethra can be determined by the signal difference between urethral tissue and prostate tissue in MR urethrography. (C,D) Sagittal T2W sequence and sagittal earlier scanning of enhanced T1W sequence of another patient. The proximal urethral end can be recognized easily in (D) because of the well-established urethral mucosa.

a single-center retrospective study based on the patients with a small sample size which was unable to support subgroup analyses according to the age, BMI, prostate size, or injury time. This definitely decreased the applicability of our parameters. In future research, by increasing the participating centers and subjects, the confounding factors can be validated and excluded. Secondly, we did not include a cost-benefit analysis. In China, the cost of a dynamic contrast-enhanced MR urethrography is usually less than 150 US dollars which is not an unacceptable price. However, in other countries and regions, the cost is high, which may limit its application. Therefore, the comparison between these two modalities of presurgical interventions, such as MR urethrography and urethrogram based on their cost-effects in implementation, needs future research. Despite these limitations, our study provided important supports for the posterior urethral reconstruction. On the one hand, our findings revealed the potential application value of $M R$ urethrography in PFUI patients and showed a practical method in combining imageology and geometry. On the other hand, it helped the urologists to make forecasting of the anastomotic urethroplasty and fully inform the patients of the probable surgical difficulties and risks.

\section{Conclusions}

Combined with geometry, MR urethrography showed significant correlation with the implementation of accurate surgical approaches of PFUI. Longer GD and shorter PUVD were the two independent factors of inferior pubectomy. In addition, among the patients with 

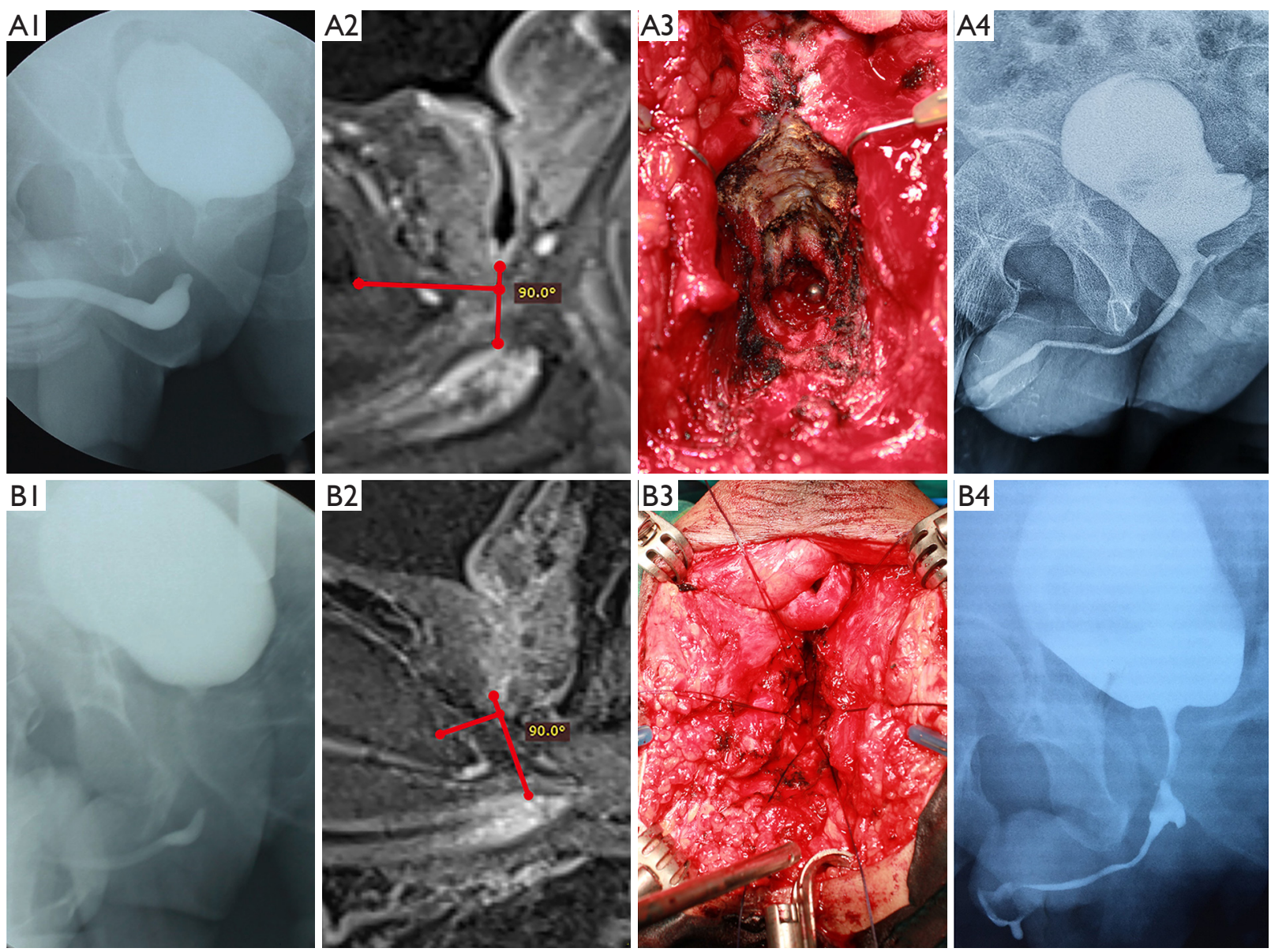

Figure 3 The two sequences of figures belonged to two patients. The figures were preoperative urethrogram, preoperative MR urethrography, intraoperative surgical approach and postoperative urethrogram respectively. Patient A underwent a corporal splitting with a $1.2 \mathrm{~cm}$ gap distance and $2.4 \mathrm{~cm}$ pubourethral vertical distance. Patient B underwent an inferior pubectomy with a $1.6 \mathrm{~cm}$ gap distance and $0.9 \mathrm{~cm}$ pubourethral vertical distance. Both of them had a satisfactory urinary flow after the delayed anastomotic urethroplasty.

a history of rectal injury, the protection of the rectum from intraoperative damage during surgical intervention is mandatory and needs strict measures for management.

\section{Acknowledgments}

Funding: This work was supported by the Open Research Fund from Shanghai Key Laboratory of Forensic Medicine (KF 1915).

\section{Footnote}

Reporting Checklist: The authors have completed the STROBE reporting checklist. Available at http://dx.doi. org/10.21037/tau-20-1064
Data Sharing Statement: Available at http://dx.doi. org/10.21037/tau-20-1064

Peer Review File: Available at http://dx.doi.org/10.21037/ tau-20-1064

Conflicts of Interest: All authors have completed the ICMJE uniform disclosure form (available at http://dx.doi. org/10.21037/tau-20-1064). The authors have no conflicts of interest to declare.

Ethical Statement: The authors are accountable for all aspects of the work in ensuring that questions related to the accuracy or integrity of any part of the work are appropriately investigated and resolved. The study was 
conducted in accordance with the Declaration of Helsinki (as revised in 2013). The study was approved by the ethics committee of Shanghai Jiao Tong University Affiliated Sixth People's Hospital (Ethic batch number: 2020-KY-007) and individual consent for this retrospective analysis was waived.

Open Access Statement: This is an Open Access article distributed in accordance with the Creative Commons Attribution-NonCommercial-NoDerivs 4.0 International License (CC BY-NC-ND 4.0), which permits the noncommercial replication and distribution of the article with the strict proviso that no changes or edits are made and the original work is properly cited (including links to both the formal publication through the relevant DOI and the license). See: https://creativecommons.org/licenses/by-nc-nd/4.0/.

\section{References}

1. Bjurlin MA, Fantus RJ, Mellett MM, et al. Genitourinary injuries in pelvic fracture morbidity and mortality using the National Trauma Data Bank. J Trauma 2009;67:1033-9.

2. Latini JM, McAninch JW, Brandes SB, et al. SIU/ICUD Consultation On Urethral Strictures: Epidemiology, etiology, anatomy, and nomenclature of urethral stenoses, strictures, and pelvic fracture urethral disruption injuries. Urology 2014;83:S1-7.

3. Xu YM, Song LJ, Wang KJ, et al. Changing trends in the causes and management of male urethral stricture disease in China: an observational descriptive study from 13 centres. BJU Int 2015;116:938-44.

4. Joshi PM, Kulkarni SB. Management of pelvic fracture urethral injuries in the developing world. World J Urol 2020;38:3027-34.

5. Martínez-Piñeiro L, Djakovic N, Plas E, et al. EAU Guidelines on Urethral Trauma. Eur Urol 2010;57:791-803.

6. Gómez RG, Mundy T, Dubey D, et al. SIU/ICUD Consultation on Urethral Strictures: Pelvic Fracture Urethral Injuries. Urology 2014;83:S48-S58.

7. Wessells H, Angermeier KW, Elliott S, et al. Male Urethral Stricture: American Urological Association Guideline. J Urol 2017;197:182-90.

8. Turner-Warwick R. Complex traumatic posterior urethral strictures. J Urol 1977;118:564-74.

9. Flynn BJ, Delvecchio FC, Webster GD. Perineal repair of pelvic fracture urethral distraction defects: experience in 120 patients during the last 10 years. J Urol
2003;170:1877-80.

10. Horiguchi A. Management of male pelvic fracture urethral injuries: Review and current topics. Int J Urol 2019;26:596-607.

11. Angermeier KW, Rourke KF, Dubey D, et al. SIU/ICUD Consultation on Urethral Strictures: Evaluation and follow-up. Urology 2014;83:S8-17.

12. Dixon CM, Hricak H, McAninch JW. Magnetic resonance imaging of traumatic posterior urethral defects and pelvic crush injuries. J Urol 1992;148:1162-5.

13. da Silva Gaspar SR, Ferreira ND, Oliveira T, et al. Magnetic Resonance Imaging and Pelvic Fracture Urethral Injuries. Urology 2017;110:9-15.

14. Narumi Y, Hricak H, Armenakas NA, et al. MR imaging of traumatic posterior urethral injury. Radiology 1993;188:439-43.

15. Oh MM, Jin MH, Sung DJ, et al. Magnetic resonance urethrography to assess obliterative posterior urethral stricture: comparison to conventional retrograde urethrography with voiding cystourethrography. J Urol 2010;183:603-7.

16. Gupta NP, Mishra S, Dogra PN, et al. Transpubic urethroplasty for complex posterior urethral strictures: a single center experience. Urol Int 2009;83:22-6.

17. Weisstein EW. Heron's formula. 2003. Available online: https://mathworld.wolfram.com/HeronsFormula.html

18. Godfrey C, Siddons AW. Modern geometry. Madison, WI: University Press, 1912.

19. Koraitim MM. Predicting risk of erectile dysfunction after pelvic fracture urethral injury in children. J Urol 2014;192:519-23.

20. Wu DL, Jin SB, Zhang J, et al. Staged pendulous-prostatic anastomotic urethroplasty followed by reconstruction of the anterior urethra: an effective treatment for longsegment bulbar and membranous urethral stricture. Eur Urol 2007;51:504-10; discussions 510-11.

21. Horiguchi A, Edo H, Soga S, et al. Pubourethral Stump Angle Measured on Preoperative Magnetic Resonance Imaging Predicts Urethroplasty Type for Pelvic Fracture Urethral Injury Repair. Urology 2018;112:198-204.

22. Wang L, Lv X, Jin C, et al. Posterior Urethroplasty Complexity and Prognosis Can be Described by a Novel Method: Posterior Urethral Stenosis Score. Urology 2018;112:186-90.

23. Lue TF, Zeineh SJ, Schmidt RA, et al. Neuroanatomy of penile erection: its relevance to iatrogenic impotence. J Urol 1984;131:273-80.

24. Childs DD, Dyer RB, Holbert B, et al. Multimodality 
imaging of the male urethra: trauma, infection, neoplasm, and common surgical repairs. Abdom Radiol (NY) 2019;44:3935-49.

25. Ha HK, Luiting HB, Graham PL, et al. Three novel methods to measure the postoperative displacement of lower urinary tract structures following radical prostatectomy in a sample of Korean patients. BMC Urol 2019;19:54.

26. Sadahira T, Mitsui Y, Araki M, et al. Pelvic magnetic resonance imaging parameters predict urinary incontinence after robot-assisted radical prostatectomy. Low Urin Tract Symptoms 2019;11:122-6.

27. Collado Serra A, Pelechano Gomez P, Martin I, et al. Magnetic resonance imaging as an assessment tool following intervention with an AdVance XP suburethral sling for postprostatectomy urinary incontinence. Neurourol Urodyn 2019;38:1616-24.

28. Sung DJ, Kim YH, Cho SB, et al. Obliterative urethral

Cite this article as: Wang Z, Song G, Xiao Y, Liang T, Wang F, Gu Y, Zhang J, Xu Y, Jin S, Fu Q, Song L. The value of MRI geometric parameters in pre-assessing the surgical approaches of pelvic fracture urethral injury. Transl Androl Urol 2020;9(6):2596-2605. doi: 10.21037/tau-20-1064 stricture: MR urethrography versus conventional retrograde urethrography with voiding cystourethrography. Radiology 2006;240:842-8.

29. Osman Y, El-Ghar MA, Mansour O, et al. Magnetic resonance urethrography in comparison to retrograde urethrography in diagnosis of male urethral strictures: is it clinically relevant? Eur Urol 2006;50:587-93; discussion 594.

30. Koraitim MM. Predictors of surgical approach to repair pelvic fracture urethral distraction defects. J Urol 2009;182:1435-9.

31. Andrich DE, O'Malley KJ, Summerton DJ, et al. The type of urethroplasty for a pelvic fracture urethral distraction defect cannot be predicted preoperatively. J Urol 2003;170:464-7.

32. Corriere JN. 1-Stage delayed bulboprostatic anastomotic repair of posterior urethral rupture: 60 patients with 1 -year follow up. J Urol 2001;165:404-7. 